Article

\title{
Decision and Coordination of Carbon Emissions Reduction Strategy in a Two-Echelon Supply Chain Considering Vertical Technology Spillovers
}

\author{
Lang Xu *, Chuanxu Wang and Hui Li \\ School of Economics and Management, Shanghai Maritime University, Shanghai 201306, China; \\ smu_bizsim@126.com (C.W.); lihui_1011@163.com (H.L.) \\ * Correspondence: jerry_langxu@yeah.net; Tel.: +86-21-3828-2490
}

\begin{abstract}
We study a two-echelon supply chain made up of a supplier and a manufacturer, both of which can reduce their component/product carbon emissions. With the vertical technology spillovers, we explore the optimal decisions of centralized and decentralized supply chains with price dependent demand and propose coordination strategy for the decentralized supply chain. Considering the cost contraction effectiveness of the technology spillovers, the centralized and decentralized game theoretic models of a two-echelon supply chain are developed to investigate optimal decisions of pricing and carbon emissions reduction. Through a systematic comparison and numerical analysis, we show that the profits of both players and the entire supply chain improve with the effect of technology spillovers increasing. Carbon emissions reduction will be taken by various protective measures so that the supplier and the manufacturer who do not innovate can hardly share the results of innovating via the "free-riding" methods when the technology spillover is relatively small. We also propose a revenue-cost sharing contract through bargaining to enhance the performance of the decentralized supply chain.
\end{abstract}

Keywords: carbon emissions reduction; technology spillover; game theory; supply chain coordination

\section{Introduction}

From "Pered Nations Framework Convention on Climate Change" to "Kyoto Protocol" and to "Copenhagen conference", the voice of energy saving is increasing, while the rapid growth of the world economy and continuous adjustment of economic structures are leading to environmental pollution and resource shortages increasingly evident. In order to achieve coordinated development of economy and the resources and the environment, the development of energy savings and reduce carbon emissions(ESER) plans to accelerate the construction of energy-saving and environmental protection standards, labeling and certification system to establish strict low-carbon products[1-2]. At present, carbon emissions reduction is regulated by the relevant government, but essentially still belongs to the external governance, the fundamental solution to reduce carbon emissions is emissions reduction investment, especially the suppliers in the upstream of supply chain. Carbon emissions reduction investment of the suppliers is to ensure the availability of low-carbon manufacturers of raw materials and reduce the cost of original raw materials.

Since the 1990s, industrial organization theory is a very active area, and affects the degree of competition and cooperation in technological innovation from the aspects of market equilibrium and social welfare. These studies have tried to analyze the impact of technology innovation on supply 
chain decisions, investigate whether the impact of technology innovation on the competitors is positive or negative, and analyze the effect of technology innovation under different products and market. Under low-carbon economy, carbon emissions reduction cooperation between enterprises is beneficial for technology sharing among enterprises, speeding up technical innovation, and improving the competitiveness of supply chain[3-5]. The increasingly fierce competition and resource constraints in production strengthen cooperation between the upstream and downstream enterprises and make the supply chain to form vertical partnership.

The innovation enables the players in supply chain to reduce the production cost, creat the mutual benefits and enhance the competitive advantage. However, R\&D is likely to cause technology spillover effect thus weakening the their competitive advantage[6-8]. The technology spillovers refer to the diffusion of technology through the promotion of technical to increase the level of productivity of other enterprises, is a manifestation of economic externalities, mainly due to the release of technical information, or with other companies for technical exchanges. The effect of technology spillovers on the innovation strategies are as the following two aspects. On the one hand due to the reduction of production cost, the firms need to develop their own technology to improve the research ability; on the other hand, the firms can be free to share the technology from the other firms' innovative with the effect of spillovers, which may damage their enthusiasm of innovation.

The rest of this paper is organized as follows. We begin by summarizing the related literature. Section 3 presents the centralized and decentralized supply chain models considering emissions reduction technology spillovers. Section 4 provides an improved revenue-sharing contract through bargaining. Section 5 presents the numerical analysis for the models. Section 6 discusses the conclusions and future research.

\section{Related Literature}

There exist two streams of researches related to our study:

(1) How are the pricing and investment strategy of the supply chain players affected by the spillover?

(2) Which coordinate mechanism can improve the performance of decentralized supply chain and achieve the Pareto optimum of players?

As mentioned before, many researchers have analyzed technology investment strategies. D'Aspremont et al.[9] established a two-stage game model with the decisions of investment and R\&D and compare the equilibrium of decentralized and centralized supply chain. Jasper et al.[10] found the duopoly market appear more cooperative and weaker competitive in the presence of the high spillover effect. Evangelia et al.[11] proposed supply chain R\&D incentives principal-agent model in the presence of technology spillover, and found that technology spillover between enterprises and R\&D cooperation are conducive to increase profits. Wang et al.[12] discusses the potential impact of 
spillover on the manufacturer's incentives, proposed the method for improving the reliability of the supply chain cooperation. Harhoff et al.[13] develops a model in which a monopolist supplier can improve the downstream product by knowledge spillovers which the downstream enterprise use as a substitute for their own R\&D efforts.

Meanwhile, Henriques et al.[14]compares the rationality of R\&D under multidimensional game perspective, and takes into account the impact of spillover and stability. Suzumura et al.[15]introduces a suboptimal function the standard of the welfare to verify the positive correlation between $R \& D$ cooperation and the profit of entire supply chain. Kamien et al.[16]analyze the effects of R\&D cartelization and research joint ventures on firms that engage in either Cournot or Bertrand competition in their product market. In the literature relating to different products in the market, Steurs et al.[17] analyzed the spillover effect between upstream and downstream enterprises and found that the vertical spillover is more effective than horizontal spillover in investment of R\&D and social welfare. Poyago et al.[18] analyzes a simple oligopoly model with information spillover, and find the equilibrium size of a research joint venture is usually less than the optimum size, which requires all enterprises to participate in the research joint venture.

Moreover, a number of papers focus on the supply chain coordination. Banerjee et al.[19] studied the vertical competing-cooperating model among upstream and downstream enterprises, and calculated the allocated incremental profits from total R\&D investment. Kim et al.[20]proposed an innovative subsidy from the manufacturer, promoting the supplier's innovation and achieving the profit of supply chain. Amir et al.[21] provided three different cost-sharing mechanisms of R\&D cooperation, income proportional sharing, product proportional sharing and fixed proportional sharing. Debabrata et al.[22] explore supply chain coordination issues arising out of green supply chain initiatives and explore the impact of cost sharing contract on the key decisions of supply chain players undertaking green initiatives. Harsanyi et al.[23] extends Nash's theory of two-person bargaining games with fixed threats to bargaining situations with incomplete information.

Based on the R\&D strategy above, all studies consider either horizontal technology spillover, or the "free rider" behavior. Our studies share a similar motivation, but comprehensively consider two dimensions - the horizontal technology spillover and the cooperation of investment, and analyze the effect of coordination mechanism on the players' cooperation strategy.

\section{Model}

In this section, we discuss the modeling assumptions, and the related decision results for a twoechelon supply chain scenarios - the centralized and decentralized, where the optimal pricing and carbon emissions reduction strategies for the supplier and the manufacturer are analyzed. The following assumptions are also needed in our model:

\section{Assumption.1}


The two-echelon supply chain consists of a supplier and a manufacturer, in which the supplier and the manufacturer are respectively the leader and follower in Stackelberg game. The supplier and the manufacturer are rational, and under the symmetric information with the technology spillovers, therefore $w>\mathrm{c}_{\mathrm{s}}$ and $p>w+c_{m}$.

\section{Assumption.2}

The manufacturer in the region forms a complete monopoly of the market, and the demand for the production is only decided by the price of product. According to the above, the market demand function is written as follows:

$$
Q=a-b p
$$

\section{Assumption.3}

The production cost generated within a single firm cannot be held privately in full, which is represented by the effect of technology spillover $\theta$, where $\theta_{1}$ represents the technological externality generated from the manufacturer's carbon emissions reduction, and $\theta_{2}$ represents the technological externality generated from the supplier's carbon emissions reduction. Technology spillovers can be interpreted as the fraction of technology that flows between firms (i.e. the higher technology spillover, the higher the frequency of technology flowing between firms), the technology absorption capacity of firms (i.e. the higher technology spillover, the greater the profit from technology flows).

\section{Assumption.4}

Carbon emissions reduction for components and products are helpful for the supplier and the manufacturer changing the old production methods and updating the obsolete machines to reduce the production cost. Thus, based on the conditions of $C^{\prime}\left(e_{i}\right)>0$ and $C^{\prime \prime}\left(e_{i}\right)>0$, we consider $C\left(e_{i}\right)$ is an increasing and convex function for carbon emissions reduction. For convenience, assume the cost of carbon emissions reduction for the supplier and the manufacturer both have quadratic mode[24]. So $C\left(e_{i}\right)$ can be given as follows

$$
C\left(e_{i}\right)=k \frac{e_{i}^{2}}{2}
$$

Where $k$ is the difficulty coefficient of carbon emissions reductions in components and products. To guarantee the existence of Stackelberg game, the difficulty coefficient should be satisfied the condition $k>2 b$.

\section{Assumption.5}

The investment of carbon emissions reductions in components and products affect the players' marginal cost with technology spillovers. And the marginal costs of component and product are given by, respectively

$$
\left\{\begin{array}{c}
c_{s}=c_{s}{ }^{\prime}-y_{s} \\
c_{m}=c_{m}{ }^{\prime}-y_{m}
\end{array}\right.
$$

where $c_{s}{ }^{\prime}$ and $c_{m}{ }^{\prime}$ are the constant marginal cost of the supplier and the manufacturer, $y_{s}=e_{1}+$ $\theta_{1} e_{2}$ and $y_{m}=e_{2}+\theta_{2} e_{1}$ are the total effect of carbon emissions reduction on contributing to reduce 
players' marginal cost[25-27].

The notation is presented as follows:

a The market potential demand

$b \quad$ The demand sensitivity coefficient on the price of product

$c_{S} \quad$ Production cost of component

$c_{m} \quad$ Production cost of product

$\theta_{1} \quad$ The positive technology spillover that the supplier receives from the manufacturer's technology of carbon emissions reductions

$\theta_{2}$ The positive technology spillover that the manufacturer receives from the supplier's technology of carbon emissions reductions

$k \quad$ The difficulty coefficient of technology for carbon emissions reduction in components and products

w Decision variable, the price per component for the supplier

$p \quad$ Decision variable, the price per product for the manufacturer

$e_{1} \quad$ Decision variable, carbon emissions reduction for the supplier

$e_{2} \quad$ Decision variable, carbon emissions reduction for the manufacturer

\subsection{Centralized supply chain}

In the centralized supply chain, the decisions are made by the supplier and the manufacturer together, namely the manufacturer and the supplier acted as a company or an organization decide supply chain systems profit. Based on the above descriptions and assumptions, the profit of supply chain can be obtained as

$$
\pi=(a-b p)\left[p-w-c_{s}-c_{m}+\left(1+\theta_{2}\right) e_{1}+\left(1+\theta_{1}\right) e_{2}\right]-\frac{k e_{1}{ }^{2}}{2}-\frac{k e_{2}{ }^{2}}{2}
$$

Apply backward induction to solve the Stackelberg game model for the centralized supply chain. Then, the first-order conditions of $\pi$ with respect to $p 、 e_{1}$ and $e_{2}$ can be given as follows:

$$
\begin{gathered}
\frac{\partial \pi}{\partial p}=a-b\left[2 p-w-c_{m}-c_{s}+\left(1+\theta_{2}\right) e_{1}+\left(1+\theta_{1}\right) e_{2}\right]=0 \\
\frac{\partial \pi}{\partial e_{1}}=(a-b p)\left(1+\theta_{2}\right)-k e_{1}=0 \\
\frac{\partial \pi}{\partial e_{2}}=(a-b p)\left(1+\theta_{1}\right)-k e_{2}=0
\end{gathered}
$$

The Hessian matrix $H\left(p, e_{1}, e_{2}\right)=\left[\begin{array}{ccc}-2 b & -b\left(1+\theta_{2}\right) & -b\left(1+\theta_{1}\right) \\ -b\left(1+\theta_{2}\right) & k & 0 \\ -b\left(1+\theta_{1}\right) & 0 & k\end{array}\right]$. We find the

determinant is less than zero when the difficulty coefficient of carbon emissions reductions meets the condition that $2 k-b\left(1+\theta_{1}\right)^{2}-b\left(1+\theta_{2}\right)^{2}>0$ (Assumption.4). The Hessian matrix $H_{I}$ for the entire supply chain profit function is a negative definite for $p_{1} e_{1}$ and $e_{2}$. Solving Eqs. (5)-(7), we have the following proposition in the centralized supply chain. 
Proposition 1.In the centralized supply chain, the equilibrium solution of price and carbon emissions reduction for the entire supply chain is as follows:

$$
\left\{\begin{array}{l}
p^{C}=\frac{a\left[k-b\left(1+\theta_{1}\right)^{2}-b\left(1+\theta_{2}\right)^{2}\right]-b k\left(c_{m}+c_{s}\right)}{b\left[2 k-b\left(1+\theta_{1}\right)^{2}-b\left(1+\theta_{2}\right)^{2}\right]} \\
e_{1}{ }^{C}=\frac{\left(a-b c_{m}-b c_{s}\right)\left(1+\theta_{2}\right)}{2 k-b\left(1+\theta_{1}\right)^{2}-b\left(1+\theta_{2}\right)^{2}} \\
e_{2}{ }^{C}=\frac{\left(a-b c_{m}-b c_{s}\right)\left(1+\theta_{1}\right)}{2 k-b\left(1+\theta_{1}\right)^{2}-b\left(1+\theta_{2}\right)^{2}}
\end{array}\right.
$$

Consequently, $\left(p^{C}, e_{1}{ }^{C}, e_{2}{ }^{C}\right)$ is the equilibrium solution to maximize the profit of centralized supply chain. Further, the profit of supply chain can be obtained as

$$
\pi^{C}=\frac{k\left(a-b c_{m}-b c_{s}\right)^{2}}{2 b\left[2 k-b\left(1+\theta_{1}\right)^{2}-b\left(1+\theta_{2}\right)^{2}\right]}
$$

\section{Proposition 2.}

(1) $\frac{\partial p^{C}}{\partial k}>0 、 \frac{\partial e_{1}{ }^{C}}{\partial k}<0 、 \frac{\partial e_{2}{ }^{C}}{\partial k}<0$;

(2) $\frac{\partial p^{C}}{\partial \theta_{1}}<0 、 \frac{\partial e_{1}{ }^{C}}{\partial \theta_{1}}>0 、 \frac{\partial e_{2}{ }^{C}}{\partial \theta_{1}}>0$;

(3) $\frac{\partial p^{C}}{\partial \theta_{2}}<0 、 \frac{\partial e_{1}{ }^{C}}{\partial \theta_{2}}>0 、 \frac{\partial e_{2}{ }^{C}}{\partial \theta_{2}}>0$;

(4) $\left\{\begin{array}{l}e_{1}{ }^{C}>e_{2}{ }^{C}, \text { if } \theta_{1}>\theta_{2} \\ e_{1}{ }^{C}=e_{2}{ }^{C}, \text { if } \theta_{1}=\theta_{2} . \\ e_{1}{ }^{C}<e_{2}{ }^{C}, \text { if } \theta_{1}<\theta_{2}\end{array}\right.$

Proposition 2 indicates that, with the difficulty coefficient of carbon emissions reduction increases, the price of product will increase and carbon emission reduction will decrease. In terms of the effect of technology spillovers on the players' production cost, we find that the players will increase carbon emissions reductions with the technology spillovers increase, while the price of product will decrease. Further, carbon emissions reductions for the supplier is more than that of manufacturer when $\theta_{1}>\theta_{2}$; carbon emissions reductions for players are equal when $\theta_{1}=\theta_{2}$; of carbon emissions reductions for the supplieris less than that of the manufacturer when $\theta_{1}<\theta_{2}$.

\subsection{Decentralized supply chain}

In the decentralized supply chain, the supplier and the manufacturer are independent and make their own decisions to maximize profits. Game sequence is as follows: First, the supplier determines the price and carbon emissions reductions for components. Then, the manufacturer makes decisions on the price and carbon emissions reduction for products. Based on the above descriptions and assumptions, the profits of the supplier and the manufacturer are represented as

$$
\begin{gathered}
\pi_{s}=(a-b p)\left(w-c_{s}+e_{1}+\theta_{1} e_{2}\right)-\frac{k e_{1}{ }^{2}}{2} \\
\pi_{m}=(a-b p)\left(p-c_{m}-w+e_{2}+\theta_{2} e_{1}\right)-\frac{k e_{2}{ }^{2}}{2}
\end{gathered}
$$


Given $w$ and $e_{1}$, the first-order conditions of $\pi_{m}$ with respect top and $e_{2}$ can be given as follows:

$$
\begin{gathered}
\frac{\partial \pi_{m}}{\partial p}=a-b\left(2 p-w-c_{m}+e_{2}+\theta_{2} e_{1}\right)=0 \\
\frac{\partial \pi_{m}}{\partial e_{2}}=a-b p-k e_{2}=0
\end{gathered}
$$

The Hessian matrix is $H\left(p, e_{2}\right)=\left[\begin{array}{cc}-2 b & -b \\ -b & -k\end{array}\right]$. We find the determinant is greater than zero when the difficulty coefficient of carbon emissions reductions meets the condition that $2 k-b>0$ (Assumption.4). Solving Eqs. (11)-(12), the optimal price and of carbon emissions reductionsfor the manufacturer are given as follows

$$
\begin{gathered}
\bar{p}=\frac{a b-a k-b k w-b k c_{m}+b k e_{1} \theta_{2}}{b^{2}-2 b k} \\
\bar{e}_{2}=\frac{-a+b w+b c_{m}-b e_{1} \theta_{2}}{b-2 k}
\end{gathered}
$$

Anticipating the manufacturer's best response, the supplier determines $w$ and $e_{1}$. Substituting $\bar{p}$ and $\bar{e}_{2}$ into Eq. (9), we take the first-order conditions of $\pi_{s}$ with respected $w$ and $e_{1}$, as follow:

$$
\begin{gathered}
\frac{\partial \pi_{s}}{\partial w}=a-b\left(2 p-c_{s}-w+\theta_{1} e_{2}+\theta_{2} e_{1}\right)=0 \\
\frac{\partial \pi_{s}}{\partial e_{1}}=(a-b p)-k e_{2}=0
\end{gathered}
$$

The Hessian matrix $H\left(w, e_{1}\right)=\left[\begin{array}{cc}\frac{2 b k\left(b-2 k+b \theta_{1}\right)}{(b-2 k)^{2}} & \frac{b k\left(b-2 k-\left(b-2 k+2 b \theta_{1}\right) \theta_{2}\right)}{(b-2 k)^{2}} \\ \frac{b k\left(b-2 k-\left(b-2 k+2 b \theta_{1}\right) \theta_{2}\right)}{(b-2 k)^{2}} & -k+\frac{2 b k \theta_{2}\left(2 k-b+b \theta_{1} \theta_{2}\right)}{(b-2 k)^{2}}\end{array}\right]$. We find the determinant is greater than zero when the difficulty coefficient of carbon emissions reductions meets the condition that $4 k-2 b\left(1+\theta_{1}\right)^{2}-b\left(1+\theta_{2}\right)^{2}>0$ (Assumption.4). Note the Hessian matrix $H_{I}$ for the decentralized supply chain profit is a negative definite. Solving Eqs. (15)-(16), we have the following proposition in the decentralized supply chain.

Proposition 3.In the decentralized supply chain, he equilibrium solutions of price and carbon emissions reductions for the supplier and the manufacturer is as follows:

$$
\left\{\begin{array}{l}
p^{D}=\frac{a\left(3 k-3 b-2 b \theta_{1}-2 b \theta_{2}-b \theta_{2}^{2}\right)+b k\left(c_{m}+c_{s}\right)}{b\left[4 k-2 b\left(1+\theta_{1}\right)-b\left(1+\theta_{2}\right)^{2}\right]} \\
w^{D}=\frac{\left(a-b c_{m}\right)\left(2 k-2 b-2 b \theta_{1}-b \theta_{2}\right)+b c_{s}\left(2 k-b-b \theta_{2}-b \theta_{2}^{2}\right)}{b\left[4 k-2 b\left(1+\theta_{1}\right)-b\left(1+\theta_{2}\right)^{2}\right]} \\
e_{1}^{D}=\frac{\left(a-b c_{m}-b c_{s}\right)\left(1+\theta_{2}\right)}{4 k-2 b\left(1+\theta_{1}\right)-b\left(1+\theta_{2}\right)^{2}} \\
e_{2}{ }^{D}=\frac{a-b c_{m}-b c_{s}}{4 k-2 b\left(1+\theta_{1}\right)-b\left(1+\theta_{2}\right)^{2}}
\end{array}\right.
$$

Consequently, $\left(p^{D}, w^{D}, e_{1}{ }^{D}, e_{2}{ }^{D}\right)$ is the equilibrium solution to maximize the profits of the decentralized supply chain. Further, the profits of the players and supply chain can be obtained as 


$$
\begin{gathered}
\pi_{s}{ }^{D}=\frac{k\left(a-b c_{m}-b c_{s}\right)^{2}}{2 b\left[4 k-2 b\left(1+\theta_{1}\right)-b\left(1+\theta_{2}\right)^{2}\right]} \\
\pi_{m}{ }^{D}=\frac{(2 k-b) k\left(a-b c_{m}-b c_{s}\right)^{2}}{2 b\left[4 k-2 b\left(1+\theta_{1}\right)-b\left(1+\theta_{2}\right)^{2}\right]^{2}} \\
\pi^{D}=\frac{k\left(a-b c_{m}-b c_{s}\right)^{2}\left(6 k-4 b-2 b \theta_{1}-2 b \theta_{2}-b \theta_{2}^{2}\right)}{2 b\left[4 k-2 b\left(1+\theta_{1}\right)-b\left(1+\theta_{2}\right)^{2}\right]^{2}}
\end{gathered}
$$

\section{Proposition 4.}

(1) $\frac{\partial p^{D}}{\partial k}>0 、 \frac{\partial e_{1}{ }^{D}}{\partial k}<0 、 \frac{\partial e_{2}{ }^{D}}{\partial k}<0$;

(2) $\frac{\partial p^{D}}{\partial \theta_{1}}<0 、 \frac{\partial e_{1}^{D}}{\partial \theta_{1}}>0 、 \frac{\partial e_{2}^{D}}{\partial \theta_{1}}>0$;

(3) $\frac{\partial p^{D}}{\partial \theta_{2}}<0 、 \frac{\partial e_{1}{ }^{D}}{\partial \theta_{2}}>0 、 \frac{\partial e_{2}{ }^{D}}{\partial \theta_{2}}>0$;

(4) $\left\{\begin{array}{l}e_{1}{ }^{C}>e_{2}{ }^{C}, \text { if } \theta_{2} \neq 0 \\ e_{1}{ }^{C}=e_{2}{ }^{C} \text {, if } \theta_{2}=0\end{array}\right.$.

Proposition 4 indicates that, with the difficulty coefficient of carbon emissions reduction increases, the price of product will increase and carbon emissions reductions will decrease. In terms of the effect of technology on the players' production cost, we find that the players will increase technology for carbon emissions reduction with the technology spillovers increase, while the price of product will decrease. Further, carbon emissions reduction for supplier is more than that of the manufacturer when $\theta_{2} \neq 0$; carbon emissions reductions for players are equal when $\theta_{2}=0$.

Proposition 5.In comparison of the equilibrium solutions obtained from the centralized and decentralized supply chain, we have:

$$
p^{C}<p^{D} ; e_{1}{ }^{C}>e_{1}{ }^{D} ; e_{2}{ }^{C}>e_{2}{ }^{D} ; \pi^{C}>\pi^{D}
$$

Proposition 5 indicates that the price of components in decentralized supply chain is higher than that in the centralized supply chain, and carbon emissions reductions for the centralized are higher than that of the decentralized. As the supply chain from decentralized into centralized, the supplier and the manufacturer maximize the profits of entire supply chain, and reduce the prices of product to increase market demand and the profits. Clearly, the reason for higher profitability of the supply chain lies in the fact that any share of carbon emissions reduction to prevent "free-riding" behavior.

\section{Supply chain coordination}

The above discussion reveals the performance of the supply chain under different scenarios. It is important to provide the contract to coordinate the players, so as to enhance the performance of decentralized. It has been proved by researchers that the centralized supply chain performs better than that of the decentralized in terms of profit maximization or cost minimization. However, it is not always possible for the players to act as a centralized system. Therefore, to ensure better result, the 
coordination between the players is essential. Combining the revenue-cost sharing contract[28-30] and supply chain bargaining[31-33], we propose an effectively coordinated mechanism.

Based on the revenue-cost sharing contract, the fraction of revenue that the manufacturer obtains is $t_{1}\left(0<t_{1} \leq 1\right)$, and the supplier obtains the remaining $1-t_{1}$ proportion of the revenue. Meanwhile, the cost of carbon emissions reduction is also shared, the fraction of cost that the manufacturer pays is $t_{2}\left(0<t_{2} \leq 1\right)$, and the supplier pays the remaining $1-t_{2}$ proportion of the cost. Therefore, the price of component $w=\left(1-t_{1}\right)\left(p-c_{m}+e_{2}+\theta_{2} e_{1}\right)+t_{1} c_{s}+e_{1}+\theta_{1} e_{2}$, and the profits of the supplier and the manufacturer are respectively as follows:

$$
\begin{gathered}
\pi_{s}=\left(1-t_{1}\right)(a-b p)\left[p-c_{s}-c_{m}+\left(1+\theta_{2}\right) e_{1}+\left(1+\theta_{1}\right) e_{2}\right]-\left(1-t_{2}\right)\left(\frac{k e_{1}{ }^{2}}{2}+\frac{k e_{2}{ }^{2}}{2}\right) \\
\pi_{m}=t_{1}(a-b p)\left[p-c_{s}-c_{m}+\left(1+\theta_{2}\right) e_{1}+\left(1+\theta_{1}\right) e_{2}\right]-t_{2}\left(\frac{k e_{1}{ }^{2}}{2}+\frac{k e_{2}{ }^{2}}{2}\right)
\end{gathered}
$$

Apply backward induction to solve the equilibrium for the decentralized supply chain. Hence, given $e_{1}$, the first-order conditions of $\pi_{m}$ with respect to $p$ and $e_{2}$ can be given as follows:

$$
\begin{gathered}
\frac{\partial \pi_{m}}{\partial p}=a t_{1}-b t_{1}\left[2 p-c_{s}-c_{m}+\left(1+\theta_{2}\right) e_{1}+\left(1+\theta_{1}\right) e_{2}\right]=0 \\
\frac{\partial \pi_{m}}{\partial e_{2}}=t_{1}(a-b p)\left(1+\theta_{1}\right)-t_{2} k e_{2}=0
\end{gathered}
$$

The Hessian matrix is $H\left(p, e_{2}\right)=\left[\begin{array}{cc}-2 b t_{1} & -b t_{1}\left(1+\theta_{1}\right) \\ -b t_{1}\left(1+\theta_{1}\right) & -k t_{2}\end{array}\right]$. We find the determinant is greater than zero when the difficulty coefficient of carbon emissions reductions meets the condition that $2 k\left(1-t_{2}\right)-b\left(1-t_{1}\right)\left[\left(1+\theta_{1}\right)^{2}+\left(1+\theta_{2}\right)^{2}\right]>0$. Note the Hessian matrix $H\left(p, e_{2}\right)$ for the profit of decentralized supply chain is a negative definite for $p$ and $e_{2}$. Solving Eqs. (22)-(23), we have

$$
\begin{gathered}
\bar{p}=\frac{k t_{2}\left[a-b c_{m}-b c_{s}+b e_{1}\left(1+\theta_{2}\right)\right]-a b t_{1}\left(1+\theta_{1}\right)^{2}}{b\left[2 k t_{2}-b t_{1}\left(1+\theta_{1}\right)^{2}\right]} \\
\bar{e}_{2}=\frac{t_{1}\left(1+\theta_{1}\right)\left[a-b c_{m}-b c_{s}+b e_{1}\left(1+\theta_{2}\right)\right]}{2 k t_{2}-b t_{1}\left(1+\theta_{1}\right)^{2}}
\end{gathered}
$$

Anticipating the manufacturer's best response, the supplier determines $e_{1}$. Substituting $\bar{p}$ and $\bar{e}_{2}$ into Eq. (20), we take the second-order derivatives of $\pi_{s}$ with $e_{1}$, and find the profit function of the supplier is strictly concave function. Then, we can obtain carbon emissions reductions

$$
e_{1}{ }^{B}=\frac{\left(1+\theta_{2}\right)\left(a-b c_{m}-b c_{s}\right)\left[2 k t_{2}^{2}\left(1-t_{1}\right)-b t_{1}^{2}\left(1-t_{2}\right)\left(1+\theta_{1}\right)^{2}\right]}{F_{1} \cdot b^{2} t_{1}^{2}\left(1-t_{2}\right)\left(1+\theta_{1}\right)^{2}+F_{2} \cdot 2 k t_{2}^{2}+F_{3} \cdot 2 b k t_{1} t_{2}}
$$

where $F_{1}=\left(1+\theta_{1}\right)^{2}+\left(1+\theta_{2}\right)^{2}, F_{2}=2 k\left(1-t_{2}\right)-b\left(1+\theta_{2}\right)^{2}, F_{3}=2\left(1+\theta_{1}\right)^{2}-t_{2}[2(1+$ $\left.\theta_{1}\right)^{2}+\left(1+\theta_{2}\right)^{2}$ ]. Substituting Eq. (26) into Eq. (25), we have

$$
e_{2}^{B}=\frac{t_{1}\left(1-t_{2}\right)\left(1+\theta_{1}\right)\left(a-b c_{m}-b c_{s}\right)\left[2 k t_{2}-b t_{1}\left(1+\theta_{1}\right)^{2}\right]}{F_{1} \cdot b^{2} t_{1}{ }^{2}\left(1-t_{2}\right)\left(1+\theta_{1}\right)^{2}+F_{2} \cdot 2 k t_{2}^{2}+F_{3} \cdot 2 b k t_{1} t_{2}}
$$


After coordinating, carbon emissions reductions for the supplier and the manufacturer are unique. By comparing $e_{1}{ }^{B}$ and $e_{2}{ }^{B}$ with carbon emissions reductions in the centralized scenario, we find $e_{1}{ }^{C}=e_{1}{ }^{B}, e_{2}{ }^{C}=e_{2}{ }^{B}$ if $t_{1}=t_{2}=t$. Then, we obtainthat the revenue-cost sharing contract can effectively coordinate the supply chain; the profits of the players are $\pi_{s}{ }^{B}=(1-t) \cdot \pi^{C}$ and $\pi_{m}{ }^{B}=$ $t \cdot \pi^{C}$, where $t_{1}=t_{2}=t$. So the parameters $t_{1}$ and $t_{2}$ are the value negotiated by the bargaining powers.

Assume that $\tau \in(0,1)$ is the bargaining power of the supplier, while that of the manufacturer is $1-\tau$. Because the supplier and the manufacturer are respectively the leader and follower, $\tau \in(0.5,1)$. Only if the supply chain achieve Pareto improvement, namely $\pi_{s}{ }^{B}(t)$ and $\pi_{m}{ }^{B}(t)$ are not less than the disagreement points $\pi_{i}{ }^{D}(i=s, m)$, the coordination mechanism can be accepted by two sides. Therefore the Nash bargaining of the supply chain is expressed as $f_{\tau}: \Theta \rightarrow \Xi$, to each $\left(\Omega, \pi_{i}{ }^{B}\right) \in \Theta$, $f_{\tau}\left(\Omega, \pi_{i}{ }^{B}\right)$ is the only solution for the revenue-cost sharing contract through bargaining. We now have the Nash bargaining model:

$$
\max \theta(t)=\left[\pi_{s}^{B}(t)-\pi_{s}^{D}\right]^{\tau}\left[\pi_{m}^{B}(t)-\pi_{m}^{D}\right]^{1-\tau}
$$

where $\Omega \equiv\left\{\begin{array}{c}\pi_{s}^{B}(t), \pi_{m}^{B}(t) \in \aleph \\ \pi_{s}^{B}(t) \geq \pi_{s}{ }^{D}, \pi_{m}^{B}(t) \geq \pi_{m}{ }^{D}\end{array}\right\}$ and $\aleph \equiv\left\{\begin{array}{c}\pi_{s}{ }^{B}(t), \pi_{m}{ }^{B}(t): 0 \leq \pi_{i}^{B}(t) \leq \pi^{C} \\ \pi_{m}{ }^{B}(t)=g\left[\pi_{s}^{B}(t)\right]=\pi^{C}-\pi_{s}{ }^{B}(t)\end{array}\right\}$. Based on the theory of Nash bargaining[34], for bargaining power $\tau$, existing $\left(\Omega, \pi_{i}{ }^{B}\right) \in \Theta$ and $\pi_{i}^{B} \geq 0$, then the solution of Nash bargaining satisfies the following equation

$$
\begin{gathered}
g^{\prime}\left[\pi_{s}{ }^{B}(t)\right]=-\frac{\tau}{1-\tau} \frac{\pi_{m}{ }^{B}(t)-\pi_{m}{ }^{D}}{\pi_{s}^{B}(t)-\pi_{s}{ }^{D}} \\
\pi_{m}{ }^{B}(t)=g\left[\pi_{s}{ }^{B}(t)\right]
\end{gathered}
$$

By solving Eqs. (29)-(30), we can find the above equilibrium solution of the proportiont is a function of bargaining power for the supplier.

$$
t^{*}=\frac{(1-\tau) \cdot\left(\pi^{C}-\pi_{s}^{D}\right)+\tau \cdot \pi_{m}^{D}}{\pi^{C}}
$$

Proposition 6.The revenue-cost sharing contract through bargaining effectively coordinated the decentralized supply chain, we have:

$$
p^{B}=p^{C} ; e_{1}^{B}=e_{1}^{C} ; e_{2}{ }^{B}=e_{2}{ }^{C} ; \pi^{B}=\pi^{C}
$$

Proposition 6 indicates that the contract through bargaining can improve the performance of the supply chain to the level of the centralized. The supplier and the manufacturer agree the contract which promises that their profits will be higher than the decentralized. Moreover, with the emissions reduction increasing and the products demand decreasing, the supply chain gets less cost and more profits. 


\section{Numerical analysis}

In this section, numerical examples are presented to illustrate the effectiveness of above model and the coordination mechanism. The values of parameters adopted in numerical examples are given as follows, the parameters are as follows: $a=20, b=0.05, c_{s}=40, c_{m}=50, \theta_{1}=0.5, \theta_{2}=0.5$, $k=10$. With the given data, results can be obtained by using Matlab software.

\subsection{Numerical example}

Table 1. Equilibrium results under different models in different scenario

\begin{tabular}{|c|c|c|c|c|c|c|c|c|c|}
\hline & & $t$ & $p$ & $w$ & $e_{1}$ & $e_{2}$ & $\pi_{s}$ & $\pi_{m}$ & $\pi$ \\
\hline \multicolumn{2}{|c|}{ Decentralized scenario } & - & 276.69 & 194.63 & 0.39 & 0.19 & 954.43 & 199.26 & 1153.68 \\
\hline \multicolumn{2}{|c|}{ Centralized scenario } & - & 152.21 & - & 1.18 & 1.18 & - & - & 1294.56 \\
\hline \multirow{6}{*}{ 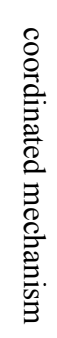 } & $\tau=0.5$ & 0.21 & 152.21 & 92.41 & 1.18 & 1.18 & 1024.87 & 269.70 & 1294.56 \\
\hline & $\tau=0.6$ & 0.20 & 152.21 & 93.11 & 1.18 & 1.18 & 1038.96 & 255.61 & 1283.52 \\
\hline & $\tau=0.7$ & 0.19 & 152.21 & 93.80 & 1.18 & 1.18 & 1053.04 & 241.52 & 1283.52 \\
\hline & $\tau=0.8$ & 0.18 & 152.21 & 94.50 & 1.18 & 1.18 & 1067.13 & 227.43 & 1283.52 \\
\hline & $\tau=0.9$ & 0.16 & 152.21 & 95.20 & 1.18 & 1.18 & 1081.22 & 213.34 & 1283.52 \\
\hline & $\tau=1$ & 0.15 & 152.21 & 95.89 & 1.18 & 1.18 & 1095.31 & 199.26 & 1283.52 \\
\hline
\end{tabular}

From Table 1, some inferences are summarized as follows :

(i) When supply chain is centralized scenario, carbon emissions reduction for the supplier and the manufacturer, and supply chain profits are improved. On the hand, the price of product is lower than that in decentralized supply chain, which means the centralized decisionmaking can enhance the overall efficiency of the supply chain.;

(ii) The revenue-cost sharing contract through bargaining has important implications for not only the improvement of supply chain performance but also the coordination between the players of supply chain. The profits of the players and entire supply chain in the coordinated mechanism are higher than that of the decentralized scenario, and the price of component and product is lower than that of the decentralized scenario. The supply chain performance is improved while the incentive compatibility constraint is satisfied through the contract to reach the effectiveness of centralized decision-making and ensure the win-win situation for the players of the supply chain;

(iii) The total profit in the coordinated scenario is constant. That means when the supplier and the manufacturer integrate as a whole system, the change of bargaining power does not affect the profit of entire supply chain. Whereas, under the impact of technology spillovers, the profit of the supplier increases as the supplier's bargaining power increases, and the profit of the manufacturer decreases. The outcome of the aforementioned negotiation agendas is unfavorable for the manufacturer, and favorable for the supplier under the equilibrium conditions. 


\subsection{Sensitivity analysis on equilibrium strategies}

We analyze and compare the strategies and profits of system and its players in different supply chain structure to investigate the impact of the difficulty coefficient of carbon emissions reduction and the technology spillovers on the equilibrium strategies.

(1) Impact of difficulty coefficient of emissions reduction

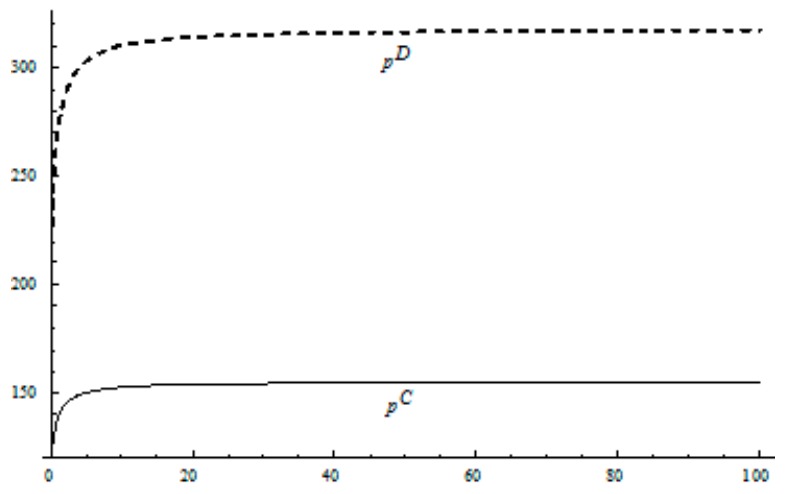

Figure 1.The impact of the difficulty coefficient on the product price

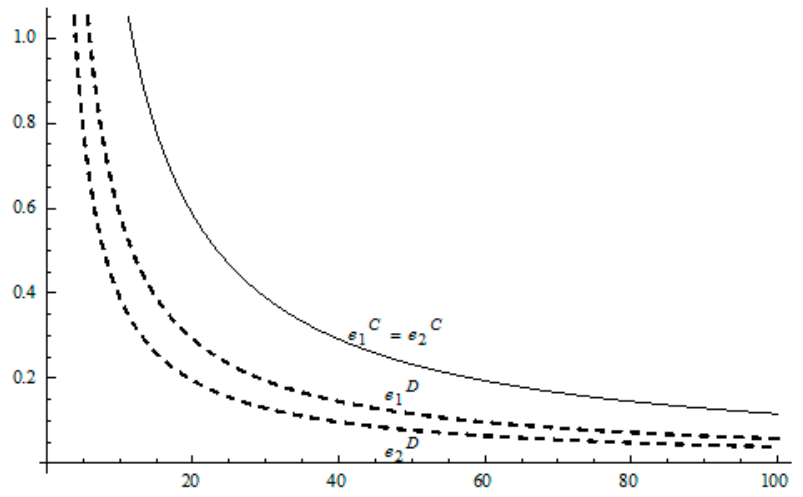

Figure 2. The impact of the difficulty coefficient on carbon emissions reduction

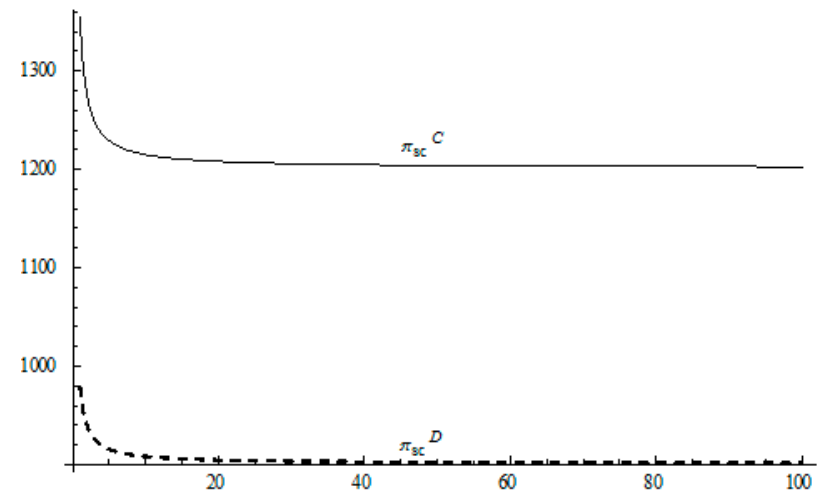

Figure 3. The impact of the difficulty coefficient on the supply chain's profit

As the difficulty coefficient of emissions reduction $k$ varies, decisions and profits in different scenarios are respectively illustrated in Figure 1-3,

(i) The difficulty coefficient of emissions reduction has a positive effect on pricing strategies $p$ in both centralized and decentralized scenario, while has a negative effect on the investment of carbon emissions reductioneand the profit of supply chain $\pi$. When the 
players invest the emissions reduction, the greater the difficulty coefficient of emissions reduction (i.e. technology restrict, cost restrict), the higher the cost of emissions reduction, the lower the investments of emissions reduction and the profits of supply chain.

(ii) It is obvious that the difficulty coefficient of carbon reduction is a major obstacle of increasing the profits of supply chain in the centralized and decentralized scenarios. To address this issue, the supply chain should give a method to take advantage of the technology spillover. When the difficulty coefficient of carbon reduction increases, the supplier as the leader of supply chain, improve the technology of carbon emissions reduction, and guide the manufacturer to increase the investment of technology, to guaranteethe profits of players and the entire supply chain.

(2) Impact of technology spillovers for carbon emissions reduction

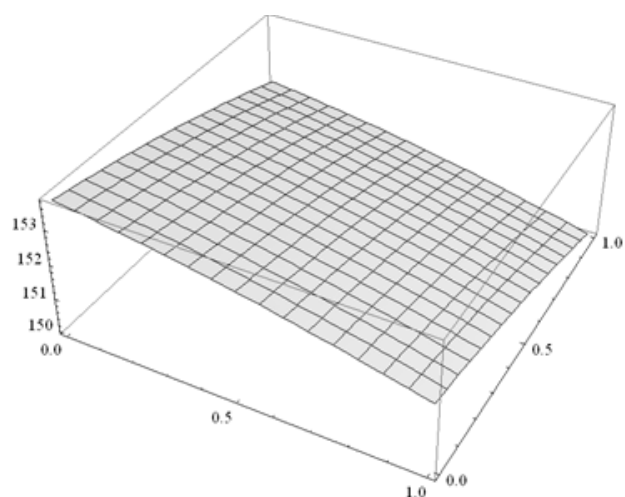

Figure 4. The impact of technology spillovers on the product price in the centralized scenario

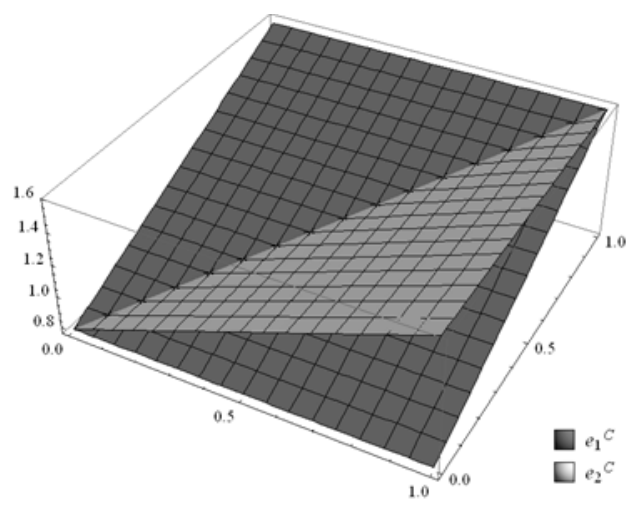

Figure 6. The impact of technology spillovers on carbon emissions reduction in the centralized scenario

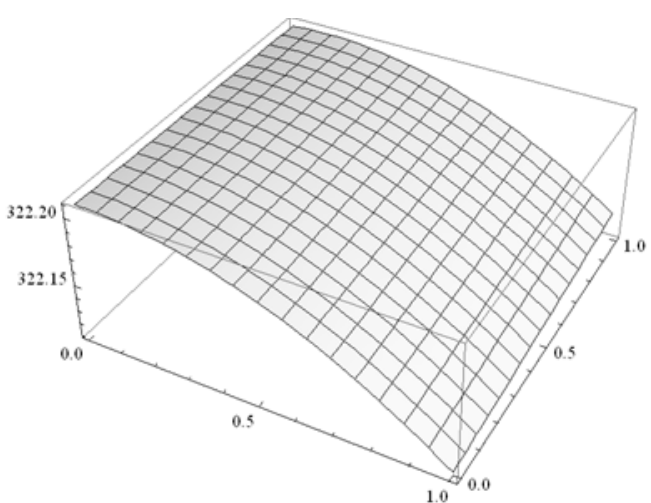

Figure 5. The impact of technology spillovers on the product pricein the decentralized scenario

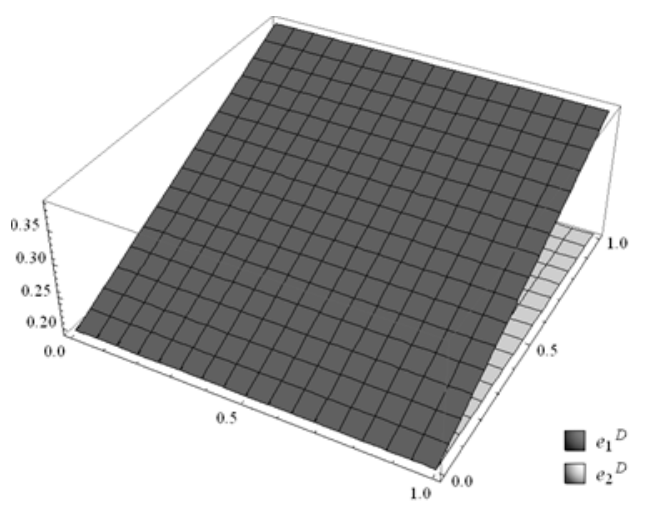

Figure 7. The impact of technology spillovers on carbon emissions reduction in the decentralized scenario 


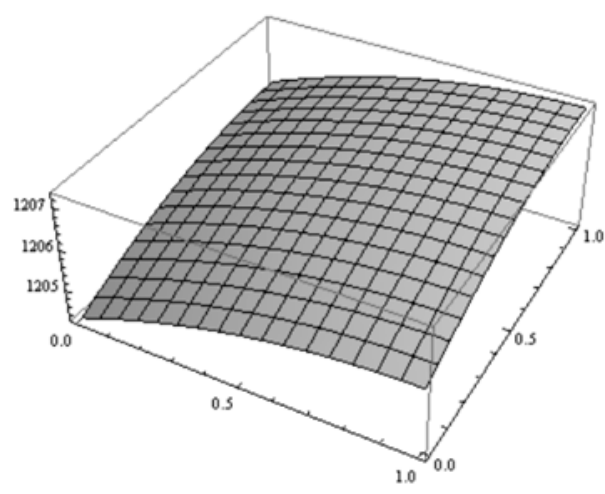

Figure 8 . The impact of technology spillovers on the supply chain's profit in the centralized scenario

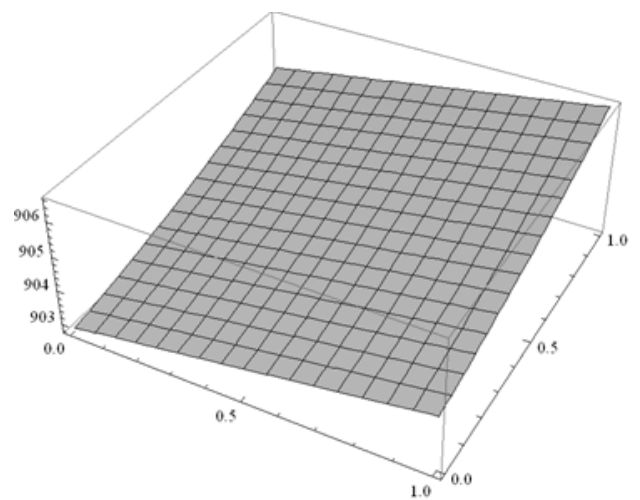

Figure 9. The impact of technology spillovers on the supply chain's profit in the decentralized scenario

As the parameters of technology spillovers $\theta$ varies, decisions and profits in different scenarios are respectively illustrated in Figure 4-9,

(i) The technology spillovers of carbon emissions reduction have a positive effect on the carbon emissions reduction for the players, and a negative effect on the pricing in the decentralized and centralized scenarios. When the technology spillovers of carbon emissions reductions are low, the production cost is high, the cost of carbon emissions reduction is also high and the price of products will be set higher. When the technology spillovers of carbon emissions reductions are high, as the production cost decreasing, the manufacturer will take advantage of the consumer's proactive response to the reduction of the product price to increase demand, and carbon emissions reduction amount of the supplier and the manufacturer will be raised emissions.

(ii) Comparing the centralized and decentralized scenarios, it is shown from in Fig.4 and Fig.5 that the price change interval in the centralized are greater than that in the decentralized with the technology spillovers increase. The similar situation also holds in carbon emissions reduction and the profit of supply chain. It can be shown from Figure 6 and Figure 8 that, in centralized supply chain, the impact of $\theta_{1}$ and $\theta_{2}$ on supply chain is obvious. The reason is that carbon emission reduction is made by the supplier and the manufacturer together to maximize the supply chain profit considering the effect of technology spillovers. Moreover, the production cost of supply chain member is reduced with the increase of technology spillovers, the product price is also decreased, and accordingly the product demand is increased. It can be shown from Figure 7 and Figure 9 that, in the decentralized supply chain, the impact of $\theta_{1}$ on supply chain carbon emissions reduction is not obvious and the impact of $\theta_{2}$ on supply chain carbon emissions reduction is obvious. This indicates that the change of carbon emissions reduction of supplier is obvious, and the change of carbon emissions reduction of manufacturer is not obvious. The reason is that the supplier acted as the leader of supply chain usually induce manufacturer to increase carbon emissions 
reduction by increase his own carbon emissions reduction. However, manufacturer considers the investment of carbon emissions reduction from the aspect of his own profit, and this will lead to the "free rider" behavior of manufacturer by employing the supplier's investment of carbon emissions reduction.

\section{Summary and future research}

Innovation is the primary measure to maintain an advance for competitions, nevertheless the technology spillover is easy to play an inhibitory effect, in which the existing literatures generally focus on the horizontal technology spillovers on the decisions of duopoly firms. While, this is the first study from the perspective of the two-echelon supply chain consisting of a single upstream supplier and a single downstream manufacture, both of whom conduct carbon emissions reduction with vertical technology spillover to reduce their costs. Using the method of dynamic game, we can obtain the equilibrium strategies of pricing and carbon emissions reduction, and coordinate the supply chain by employing the revenue-cost sharing contract through bargaining to. In our work, our work gets several findings.

(i) Whether it is the centralized or decentralized scenarios, the profits and carbon emissions reduction always increase with the technology spillovers increasing, conversely the price of product decrease. When there is technology spillover effect in the decentralized scenario, the manufacturer may not benefit from the increased technology investment of supplier, and carbon emissions reduction of manufacturer is less than that of the supplier as the technology spillovers increases. Whereas, the players can benefit from the increased technology investment of partner in the centralized scenario, and carbon emissions reduction of the players is equal.

(ii) With the difficulty coefficient increases, carbon emissions reduction will decrease. The players of supply chain will take various protective measures to the technologies, when the technology spillovers are relatively small. The supplier as the leader of supply chain, improve the technology of carbon emissions reduction, and guide the manufacturer to increase the technology investment, to guarantee the profits of players and the entire supply chain.

(iii) The revenue-cost sharing contract through bargaining enhance the performance of decentralized supply chain perfectly to reach that of centralized supply chain, without harming the players' profits. It is beneficial for the supplier and manufacturer, and the proportions of revenue-cost allocation depend on the bargaining powers of them.

However, our research have several studies can be carried for future. First, we assume the demand is only influenced by the price, while an extension study should take a multi-factor demand model. Second, our study is based on two-echelon supply chain with a single supplier and a single 
manufacturer, the more complicated supply chain with three-echelon can be incorporated inthe future research.

\section{Acknowledgements}

This research is supported by National Natural Science Foundation of China (Grant No. 71373157). Particularly, the authors would like to acknowledge the editor and anonymous referees for their careful reading and constructive comments. These comments are valuable and make for a stronger paper.

\section{References}

1. Jonathan I. Levy, May K. Woo, Yann Tambouret. Energy savings and emission reductions associated with increased insulation for new homes in the Pered States. Building and Environment. 2016, 96, 72-79.

2. Werner Antweiler, Sumeet Gulati. Scrapping for clean air: Emission savings from the BC SCRAPIT program. Journal of Environmental Economics and Management. 2015, 71, 198-214.

3. Sungchul Choi, Paul R. Messinger. The role of fairness in competitive supply chain relationships: An experimental study.European Journal of Operational Research. 2016, 251, 798-813.

4. Kihyun Park, Hokey Min, Soonhong Min. Inter-relationship among risk taking propensity, supply chain security practices, and supply chain disruption occurrence. Journal of Purchasing and Supply Management. 2016, 22, 120-130.

5. Divesh Kumar, Zillur Rahman. Sustainability adoption through buyer supplier relationship across supply chain: A literature review and conceptual framework. International Strategic Management Review. 2015, 3, 110-127.

6. Jasper Veldman, Gerard J.C. Gaalman. Competitive investments in cost reducing process improvement: The role of managerial incentives and spillover learning. International Journal of Production Economics. 2015, 170, 701-709.

7. Takashi Shibata. Market structure and R\&D investment spillovers. Economic modeling. 2014, 43, 321-329.

8. Olov H.D. Isaksson, Markus Simeth, Ralf W. Seifert. Knowledge spillovers in the supply chain: Evidence from the high tech sectors. Research Policy. 2016, 45, 699-706.

9. D'Aspremont C., JacqueminA.. Cooperative and noncooperative R\&D in duopoly with spillovers. The American Economic Review. 1988, 78, 1133-1137.

10. Jasper Veldman, Gerard J.C.. Competitive investments in cost reducing process improvement: The role of managerial incentives and spillover learning. International Journal of Production Economics. 2015, 170, 701-709.

11. Evangelia Chalioti. Incentive contracts under product market competition and R\&D spillovers. Economic Theory. 2015, 58, 305-328.

12. Yiming Wang, Yixuan Xiao, Nan Yang. Improving reliability of a shared supplier with competition 
and spillovers. European Journal of Operational Research. 2014, 236, 499-510.

13. Harhoff D.. Strategic spillovers and incentives for research and development. Management Science. 1996, 42, 907-925.

14. Henriques I.. Cooperative and Non-cooperative R\&D in duopoly with spillovers comment. The American Economic Review. 1990, 80, 1133-1137.

15. Suzumura K.. Cooperative and Non-cooperative R\&D in oligopoly with spillovers. The American Economic Review. 1992, 82, 1307-1320.

16. Kamien M.I., Muller E. Zang L.. Research joint ventures and R\&D cartels. The American Economic Review. 1992, 80, 1293-1306.

17. Steurs G.. Inter-industry R\&D spillover: What difference do they make? International Journal of Industial Organization. 1995, 13, 249-276.

18. Poyago J.. Equilibrium and optimal size of a research joint ventures in an oligopoly with spillovers. Journal of Industry Economics. 1995, 43, 209-225.

19. Banerjee S., Lin P.. Vertical research joint ventures. International Journal of Industial Organization. 2001, 19, 285-302.

20. Kim B.. Coordinating an innovation in supply chain management. European Journal of Operational Research. 2000, 123, 568-584.

21. Amir R., Muller E.. Research joint venture and R\&D Cartels. International Journal of Industial Organization. 2000, 18, 1013-1032.

22. Debabrata Ghosh, Janat Shah. Supply chain analysis under green sensitive consumer demand and cost sharing contract. International Journal Production Economics. 2015, 164, 319-329.

23. Harsanyi J.C., SeltenR.. A generalized Nash bargaining solution for two-person bargaining games with incomplete information. Management Science. 1972, 18: 80-106.

24. Sudheer Gupta, Richard Loulou. Process innovation, product differentiation, and channel structure: Strategic incentives in a duopoly. Marketing Science. 1998, 17, 301-316.

25. Slim Ben Youssef. Transboundary pollution, R\&D spillovers and international trade. Ann Reg Sci. 2009, 43, 235-250.

26. Roberto Cellini, Luca Lambertini. Dynamic R\&D with spillovers: Competition vs cooperation. Journal of Economic Dynamics \& Control. 2009, 33, 568-582.

27. Shinji Kobayashi. On a Dynamic Model of Cooperative and Non-cooperative R\&D in Oligopoly with Spillovers. Dyn Games Appl. 2015, 5, 599-619.

28. Debasmita Basak, Leonard F.S. Wang. Endogenous choice of price or quantity contract and the implications of two-part-tariff in a vertical structure. Economics Letters. 2016, 138, 53-56.

29. Krina Griva, Nikolaos Vettas. On two-part tariff competition in a homogeneous product duopoly. International Journal of Industrial Organization. 2015, 41, 30-41.

30. Juhong Gao, Hongshuai Han, LitingHou, et al. Pricing and effort strategiess in a closed-loop supply chain under different channel power structures. Journal of Cleaner Production. 2016, 112, 
2043-2057.

31. Desheng Dash Wu. Bargaining in supply chain with price and promotional effort dependent demand. Mathematical and Computer Modelling. 2013, 58, 1659-1669.

32. Jiuh-Biing Sheu, Xiao-Qin Gao. Alliance or no alliance-Bargaining power in competing reverse supply chains. European Journal of Operational Research. 2014, 233, 313-325.

33. Desheng Wu, Opher Baron, Oded Berman. Bargaining in competing supply chains with uncertainty. European Journal of Operational Research. 2009, 197, 548-556.

34. Nash J.F.. The bargaining problem[J]. Econometrica. 1950, 18, 155-162.

(C) 2016 by the authors; licensee Preprints, Basel, Switzerland. This article is an open access article distributed under the terms and conditions of the Creative Commons by Attribution (CC-BY) license (http://creativecommons.org/licenses/by/4.0/). 